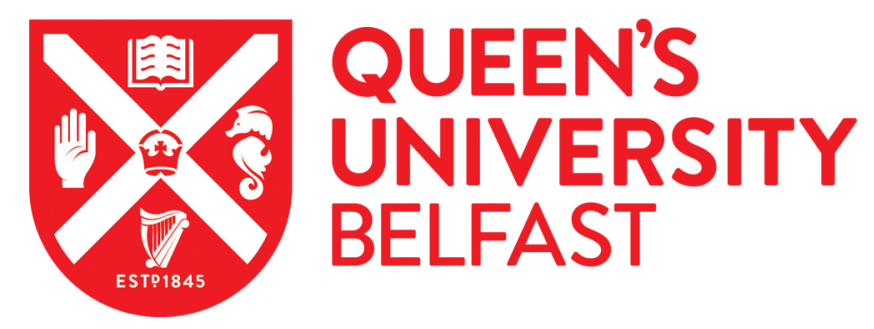

\title{
Understanding the Hangover Experience in Canadian Adults: A Latent Class Analysis of Hangover Symptom Patterns and their Alcohol Related Correlates
}

Shorter, G. W., Murphy, M., \& Cunningham, J. A. (2017). Understanding the Hangover Experience in Canadian Adults: A Latent Class Analysis of Hangover Symptom Patterns and their Alcohol Related Correlates. Drugs: Education, Prevention and Policy, 24(2), 189-196. https://doi.org/10.1080/09687637.2016.1178709

Published in:

Drugs: Education, Prevention and Policy

Document Version:

Peer reviewed version

Queen's University Belfast - Research Portal:

Link to publication record in Queen's University Belfast Research Portal

\section{Publisher rights}

Copyright (C 2020 Informa UK Limited

This work is made available online in accordance with the publisher's policies. Please refer to any applicable terms of use of the publisher.

\section{General rights}

Copyright for the publications made accessible via the Queen's University Belfast Research Portal is retained by the author(s) and / or other copyright owners and it is a condition of accessing these publications that users recognise and abide by the legal requirements associated with these rights.

Take down policy

The Research Portal is Queen's institutional repository that provides access to Queen's research output. Every effort has been made to ensure that content in the Research Portal does not infringe any person's rights, or applicable UK laws. If you discover content in the

Research Portal that you believe breaches copyright or violates any law, please contact openaccess@qub.ac.uk. 
This article is the pre-print version of the article currently in Online First at Drugs: Education, Prevention \& Policy

Shorter, G. W., Murphy, M., \& Cunningham, J. A. (2016). Understanding the hangover experience in Canadian adults: A latent class analysis of hangover symptom patterns and their alcohol-related correlates. Drugs: Education, Prevention and Policy, 1-8.

The post-print, and most recent version of the article can be located at http://www.tandfonline.com/doi/full/10.1080/09687637.2016.1178709

Understanding the Hangover Experience in Canadian Adults: A Latent Class Analysis of Hangover Symptom Patterns and their Alcohol Related Correlates.

Gillian W. Shorter PhD ${ }^{1,2}$, Michelle Murphy BSc ${ }^{3}$, John A. Cunningham PhD ${ }^{2,3}$

${ }^{1}$ Trinity Centre for Practice and Healthcare Innovation, School of Nursing and Midwifery, Trinity College Dublin, the University of Dublin, Dublin, Ireland

${ }^{2}$ National Institute for Mental Health Research, Australian National University, Canberra, Australia

${ }^{3}$ Department of Social and Epidemiological Research, Centre for Addiction and Mental Health, Toronto, Canada

Correspondence to:

Dr Gillian W. Shorter

Address: Trinity Centre for Practice and Healthcare Innovation, School of Nursing and Midwifery, Trinity College Dublin, the University of Dublin, 24 D’Olier Street, Dublin 2, Ireland E-mail:Gillianwshorter@gmail.com

Telephone: +35318964689 
RUNNING HEAD: Alcohol hangover patterns and correlates in Canadian Adults

Acknowledgements/Funding Source: This research was supported from funds attached to JC's

Canada Research Chair in Brief Interventions for Addictive Behaviours.

Conflicts of Interest: None. 
RUNNING HEAD: Alcohol hangover patterns and correlates in Canadian Adults

Understanding the Hangover Experience in Canadian Adults: A Latent Class Analysis of Hangover Symptom Patterns and their Alcohol Related Correlates.

\section{Abstract}

Aim: Given the ubiquitous nature of hangover experience amongst drinkers, this study aimed to profile hangover experience in terms of the number and patterns of past year symptoms.

Methods: Current drinkers in Canada $(n=565)$ recruited through zoompanel were asked about 13 past year hangover symptoms. These were explored through correlation with alcohol consumption, problems, treatment, and other factors.

Findings: Increased number of symptoms were associated with higher AUDIT problem score, perceived harm from drinking, younger age, and flushing/blushing when drinking (Mean=3.3 symptoms). Four patterns were found from Latent Class Analysis; class 4 (43\%) no symptoms;

class $3(13 \%)$ thirst, tiredness, headache, nausea, and vomiting; class $2(22 \%)$ thirst, tiredness, and headache; and class 1 (21\%) wide range. Class 1 were characterized by blushing when drinking, higher perceived harm, and attempts to reduce drinking due to hangovers. Classes 1-3 were associated with heavier consumption; only class 3 compared to class 4 had lower drinking refusal self-efficacy. Conclusions: Higher alcohol consumption and lower drinking refusal self-efficacy relate to more symptoms; however, a group with variable alcohol consumption did not experience hangovers. The link between problems, treatment, and hangover was not clear from patterns of symptoms; symptom severity may be worth further investigation.

Keywords: Hangover; alcohol consumption; Hangover Symptoms Scale; latent class analysis; alcohol problems, alcohol hangover, hangover experience, Alcohol Use Disorders Identification Test 
RUNNING HEAD: Alcohol hangover patterns and correlates in Canadian Adults

Understanding the Hangover Experience in Canadian Adults: A Latent Class Analysis of

Hangover Symptom Patterns and their Alcohol Related Correlates

\section{Introduction}

Hangovers, or the range of negative symptoms experienced following a drinking episode, are a commonly reported consequence of alcohol consumption (Wiese et al., 2000). These negative symptoms can have considerable physical, psychiatric, and occupational costs. For example, Gjerde et al. (2010) reported reduced workplace safety and productivity amongst Norwegian employees. In their sample, $6.2 \%$ were absent due to hangover, and $24.3 \%$ presented at work with a hangover in the past year. The latter group have important implications given the proportion of the Norwegian workforce employed in transport related occupations, and the cognitive deficits associated with experiencing hangover. There is an assumed link between experiencing hangovers and current or future problematic alcohol use, but the nature and mechanisms are not well developed (Piasecki et al., 2005; Piasecki et al., 2010; Rohsenow et al., 2012). Regular experience of a hangover is also an independent risk factor for poorer health; Kauhanen et al. (1997) reported those experiencing hangovers at least once per month had a 2.4-fold increased risk of cardiovascular death compared to those without whilst controlling for age and alcohol consumption.

Despite the societal cost of hangover symptoms, the characteristics of those experiencing different types of hangover symptoms are not well understood. Much of the hangover research focusses on younger adults, which limits the understanding of hangover experience across the life course. One exception, a study of 51,645 adults aged 18-94 in Denmark, suggested the severity of hangover was lower in older adults when controlling for alcohol consumption, frequency of binge drinking, and the consumption of alcohol with meals (Tolstrup et al., 2014). Hesse and Tutenges (2010) concluded there were no differences in hangover experience by sex (controlling for alcohol 
RUNNING HEAD: Alcohol hangover patterns and correlates in Canadian Adults consumption in holidaymakers at a beach resort). Howland et al. (2010) also found few sex differences in hangover experience when the breath alcohol levels were controlled for in a laboratory setting. However, women were more likely to experience hangover symptoms even though they typically drank less than men. It has been suggested women may be more susceptible to the unpleasant acute effects from alcohol including hangover symptomatology (Slutske et al., 2003), but there is limited information to determine whether specific symptoms might be particularly characteristic.

A severe hangover is considered to punish overindulgence and discourage future alcohol use (Epler et al., 2014). Hangover avoidance may be a reason to limit alcohol use, however, there are measurable individual differences in the willingness to experience a hangover (Mallett et al., 2011) and avoidance may also depend on the ability to refuse alcohol in situations where it is common to consume alcohol (Oei et al., 2005). Hangovers are not just associated with heavy drinking; some individuals in Asian communities or other individuals with specific acetaldehyde dehydrogenase related genotypes have symptoms such as flushing or blushing after only one or two drinks (Slutske et al., 1995). Furthermore, around $20-25 \%$ of the population are thought to be resistant to hangover (Howland et al., 2008).

Given hangovers are a frequent consequence of alcohol use with considerable negative impacts on health, risk, work, and everyday function, this study aimed to profile hangover experience in terms of both the number and patterns of past year symptoms reported by Canadian drinkers. Empirical methods may offer an alternative explanation of associations with covariates; might certain patterns of symptoms that occur together over a period be associated with greater problems, higher consumption, higher treatment seeking, or a reduced ability to refuse alcohol in settings where it is commonly consumed? The aim of this paper is to understand the measurement of hangover experience, through the two methods of measurement, and to assess 
RUNNING HEAD: Alcohol hangover patterns and correlates in Canadian Adults

how these methods can develop our understanding of relationships with background characteristics, alcohol use and consequences, treatment use, and drinking refusal self-efficacy in common settings.

\section{Materials and Methods}

\section{Participants and data}

Recruited participants were from the Zoom Panel (MarketTools, Inc.) online community, surveyed in January 2013. In total, 579 individuals consented to take part. Eligible individuals were aged 18 or over, lived in Canada, and were a current drinker (consumed at least one alcoholic drink in the past year). Following listwise deletion, the effective sample size was 565; five consented but did not answer any questions, one was aged 13, three lived outside of Canada, four did not answer alcohol questions (thus we could not confirm eligibility), and one stated s/he referred to alcohol and drug hangovers. All were compensated through points, which once accumulated, can be redeemed as vouchers (Zoom Panel Incentives program). The study was completed online. Of the participants, $54.3 \%$ were female; the mean age was 46.8 years ( $S D=15.6$; range $18-92$ ). Ethical approval was granted from the Centre for Addiction and Mental Health Ethics Review Board prior to data collection and informed consent was obtained from all participants.

\section{Measures}

\section{Background characteristics}

Demographic information included sex (male=0; female=1), age (in years); education level (did not complete High School, completed High School, completed Community College, completed University or Higher University degree), relationship status (married/living with partner, separated/divorced, widowed, single), employment status (full-time employed, part-time 
RUNNING HEAD: Alcohol hangover patterns and correlates in Canadian Adults employed, student, economically inactive), gross family income (less than 30,000CAD, 30,00049,000CAD, 50,000-79,000CAD, 80,000+ CAD), and Ethnicity (White, Asian or Mixed Asian, Other).

\section{Alcohol and hangover measurement}

Alcohol use and related problems were assessed using the Alcohol Use Disorders Identification Test (AUDIT; (Saunders et al., 1993; Babor et al., 2001), a 10-item scale measuring past year alcohol use. It has a replicable two factor structure, with items 1-3 (AUDIT-C; alcohol consumption factor) measuring alcohol use, and items 4-10 (AUDIT-P; alcohol problems factor) measuring alcohol related problems (Shevlin \& Smith, 2007). Reinert and Allen (2002) noted good internal reliability over 18 studies (median Cronbach's alpha >0.8) and good test-retest reliability in 3 studies (range 0.64-0.92). Individuals were asked to summarise their personal risk for a serious health problem due to their own alcohol use ( $1=$ no risk to $6=$ high risk). They were also asked whether they had seen a physician, counsellor, Alcoholics Anonymous, or any other community agency or professional in relation to their alcohol use (yes $=1 ;$ no $=0$ ). The ability to refuse alcohol in certain social situations was measured using the "Social pressure" factor (DRSEQ-R-SP) of the Drinking Refusal Self-Efficacy questionnaire- Revised (Oei et al., 2005). This factor has excellent reliability in a community sample with Cronbach's alpha of 0.95 (Oei et al., 2005). Participants are asked to rank the likelihood they would consume alcohol in five different scenarios, with scores on each item ranging from 1 (I am very sure I would drink) to 6 (I am sure I would not drink). Total scores range from 5 to 30 with a higher score representing a higher ability to refuse alcohol. The five situations presented to the participant are: how easy do you find it to refuse alcohol (a) when you are out for dinner, (b) when you are offered a drink, (c) when your spouse/partner is drinking, (d) when your friends are drinking, or (e) when you are at a pub/club. Respondents were asked whether they had (1) or had not (0) experienced a flush or blush-that is, their face and hands felt hot and face turned red after only one or two drinks (Bucholz et al., 1994). Hangover symptoms were measured from a list of 13 symptoms, present (1) or absent (0) in the past year, from the 
RUNNING HEAD: Alcohol hangover patterns and correlates in Canadian Adults Hangover Symptoms Scale (Slutske et al., 2003). Reliability of this scale in a community sample was good with Cronbach's alpha of 0.78 (Robertson et al., 2012).

\section{Analysis}

Data were recoded and analysed in SPSS version 22 (IBM Corp, New York, US) and Mplus version 6 (Muthen \& Muthen, 1998-2014). A multivariate regression model was used to explore the association of age, sex, AUDIT-C, AUDIT-P, alcohol help seeking, perceived harm from alcohol use, score on DRSEQ-SP and flushing or blushing after one or two drinks of alcohol with a) total number of symptoms in the past year and b) patterns of symptoms experienced in the last year. A multivariate approach was preferred to understand relations with covariates above and beyond knowing how much a person drinks. Patterns of symptoms experienced were generated using Latent Class Analysis on the presence or absence of the 13 hangover symptoms. For the purposes of multinomial logistic regression, the latent class model parameters were fixed, and thus the correlates did not affect the formation of the latent variable. The separation of covariates and indicators of the latent class variable was chosen as it helps establish the predictive validity of the classes. If resultant classes are distinct, rather than cut off points on a continuum, they should differ in their relationships with a single covariate whilst controlling for the effect of others. Criteria for selection of the best latent class model were lowest AIC, BIC and Sample size adjusted BIC, and LRT following methods used by others including Smith et al. (2011) and Smith and Shevlin (2008). Fit criteria are included in Appendix 1.

\section{Results}

Characteristics of the sample are given in Table 1. Most were married or cohabiting (60.9\%), of White ethnic origin (90.2\%), full-time employed (44.9\%), or economically inactive (excluding current students; 38.5\%), with an annual income of over 50,000CAD. The mean AUDIT score was $6.4(S D=5.7)$ and $28.3 \%$ had an AUDIT score of eight or more indicating hazardous drinking $(n=152$; 
RUNNING HEAD: Alcohol hangover patterns and correlates in Canadian Adults

$24 \%$ females and 33\% males). Using the AUDIT score of six or more to indicate hazardous drinking for females, the percentage of females considered drinking in a range that puts their health at risk is now $35 \%$ and the overall total of hazardous drinkers in the sample increases to $34.2 \%$ ( $n=184$ ). The AUDIT consumption factor score was significantly higher in males compared to females; however, the scores on the AUDIT problems factor did not differ. Around $8 \%$ had sought help in relation to their alcohol use. Females were significantly better at refusing alcohol in situations where alcohol was commonly consumed measured by the DRSEQ-R-SP and were considerably more likely to flush or blush following the consumption of one or two drinks (47.6\% v $18.2 \%)$.

TABLE 1 approximately here

Around $65 \%$ had at least one symptom in the past year, with a mean number of 3.3 symptoms experienced over the year. Of these the most common were feeling thirsty (49.9\%), headache (48.0\%), and feeling tired (42.4\%). There were only two symptoms for which there were sex differences. These were sensitivity to light and sound, and nausea both of which were more frequently experienced by Females. The least common symptom was trembling or shaking experienced by around $9 \%$ of individuals in the past year.

TABLE 2 approximately here

A multiple regression was performed to predict the number of hangover symptoms in the past year; around $28.3 \%$ of the variability was explained by the covariates (Table 2 ). The strongest predictor of the number of symptoms was increased AUDIT problem score followed by age, where younger individuals were associated with increased number of symptoms. Other significant correlates included perceived harm from drinking and flushing and blushing when drinking one or 
RUNNING HEAD: Alcohol hangover patterns and correlates in Canadian Adults

two drinks. There was no significant association with alcohol treatment, sex, or drinking refusal self-efficacy.

A series of latent class analysis models were run to determine patterns of hangover experience in the past year. Fit criteria revealed the best fit to the data to be a four class solution due to lowest values of AIC, BIC and SSABIC (see Supplementary Online Table 1). The nature of these four classes is shown in Figure 1. The largest of these four classes represented a group which was largely symptom free (42.5\%). As Table 3 illustrates this group was the oldest of the four and around $48 \%$ were male. They were lowest on all alcohol measures, and had the highest mean score on the drinking refusal self-efficacy social pressure factor. Class three was characterised by the hangover symptoms of thirst, tiredness and headache, representing $23.9 \%$ of the sample. They were younger than class four with a mean age of 47.3 years but had a similar percentage of males and females. Around one quarter drank five or more drinks on occasion, monthly or more frequently, with a mean total AUDIT score of around 5.6 (SD=3.8). Members of class two were similar to class three; however, this class also experienced nausea and vomiting. They were also different in their characteristics to class three, they were younger (mean age=38.6 years; $S D=11.2$ ) and had slightly more females than males ( $58.7 \%$ female; $41.3 \%$ male). This class had the heaviest alcohol use. Their mean AUDIT total score was 11.6, with the highest mean AUDIT consumption and problems factor scores, and highest perceived harm from alcohol. Around one quarter had sought treatment for their alcohol problems in the past, and this group had the lowest drinking refusal self-efficacy social pressure score. Class one had the highest probability of endorsing all hangover symptoms (with the exception of vomiting, most likely endorsed in class three). This class also had endorsement probability of over $50 \%$ for all symptoms except trembling. Despite having the widest range of symptoms, and the largest endorsement probability, those in class one drank less than those in class two, they had a lower score on AUDIT problems factor to class two, had a 
RUNNING HEAD: Alcohol hangover patterns and correlates in Canadian Adults slightly higher drinking refusal self-efficacy social pressure score, and perceived their harm from alcohol to be less than those in class two.

INSERT TABLE 3 and FIGURE 1 approximately here

A multinomial logistic regression was performed to predict membership of the different types of hangover experience in the past year using class four (the symptom free group) as the comparison group. The multivariate predictors were age, sex, AUDIT consumption, AUDIT problems, treatment use, flushing or blushing, DRSEQ-R-SP and perceived harm from alcohol (Table 4). Younger age and heavier alcohol consumption (AUDIT-C) was significantly associated with all three hangover classes compared to class four. Those in class one were more likely to flush or blush when they drank one or two drinks, and more likely to perceive their harm from alcohol to be higher than the no hangover group. Class three who experienced thirst, tiredness, and headache also were significantly more likely to experience flushing or blushing when consuming smaller amounts of alcohol, but with a lower odds ratio than Class one. Class three were also significantly less likely to be able to refuse alcohol in social situations compared to class four.

INSERT TABLE 4 approximately here

\section{Discussion}

This paper aimed to assess the experience and correlates of hangover in the past year drawing upon the number and patterns of symptoms experienced by a sample of Canadian adults. Four classes of hangover experience were found, with a mean number of symptoms of around three different symptoms over the year. The most common of these three symptoms, feeling extremely thirsty, more tired than usual, and experiencing a headache were characteristic of the three hangover classes, in line with other research using the Hangover Symptoms Scale (e.g. Slutske et 
RUNNING HEAD: Alcohol hangover patterns and correlates in Canadian Adults al., 2003). However, there was divergence in classes one through three. Class one experienced multiple additional hangover symptoms, and class two also experienced nausea and vomiting symptoms in addition to the characteristics typical of class three (feeling extremely thirsty, feeling more tired than usual, and experiencing a headache). Given class one drank less overall than class two, there appear to be considerable individual differences in how the after effects of alcohol consumption are felt, that do not seem to be fully explained by the amount consumed. Members of class two may have adapted to a high drinking load, or are more practiced drinkers. However, given the significant association with flushing/blushing when consuming one or two drinks in class one compared to the no hangover baseline class, this may be evidence that the wider range of symptoms is associated with a reduced ability to tolerate alcohol, rather than volume of alcohol consumed on the drinking occasion.

The percentage of adults who were hangover free in the past year is higher than others' findings at around $35 \%$ of those sampled. The latent class with the lowest endorsement of any symptoms had a slightly higher percentage of membership (42.3\%) but this group contained some who only experienced one of the symptoms. Howland et al., (2008) in a review of survey findings suggested a mean of $23.6 \%$ did not experience a hangover with a range of $13-35 \%$ in other studies.

This finding may reflect differing reference periods, and lack of consistency in measuring alcohol consumption and hangover symptoms across surveys. For example, the National Epidemiologic Survey on Alcohol and Related Conditions (NESARC) in 2001-2002 asked about "bad after effects" when alcohol leaves the system referring to heavy drinking experiences ever or in the past year. Measurement in this paper, with the established Hangover Symptom Scale (Slutske et al., 2003), covered 13 different symptoms, some of which may not be referred to as "bad after effects". Symptoms such as tiredness may be attributed to staying up late rather than a consequence of alcohol use, and consequently, the percentage of those endorsing this item might be higher when 
RUNNING HEAD: Alcohol hangover patterns and correlates in Canadian Adults it is contained in a questionnaire that prompts it as a hangover experience. The attribution of "bad" to the after effects is problematic given the variation in tolerance of negative experiences by drinkers (Mallett et al., 2011). And for some the importance of the "hangover war story"- a descriptor of the 'worst hangover ever' prefaced by a drinking occasion, with an interesting narrative of the severity of symptoms, tales of social interaction, and/or risks to health and safety.

The role of alcohol consumption was considered as an explanatory factor for the high prevalence of no hangovers in this sample. Indeed, we included drinking five or more drinks when describing the latent classes found. It may be interesting to explore different characteristics of drinking as covariates rather than the composite AUDIT consumption score in future research to understand the link between consumption, and the presence or absence of hangover symptoms or patterns of symptoms. Around 13\% of those in the symptom free class four drank five or more drinks on occasion, monthly or more frequently, suggesting there is a subset of people who can drink this amount without a reported hangover. Other studies provide support, for example, of those who had consumed five or more drinks on at least one drinking occasion in the past year, $26.7 \%$ did not report experiencing a hangover (Howland et al., 2008). However, the reporting of no hangover depends on the attribution of alcohol to any hangover symptoms experienced; for example, someone may suffer from low mood after a heavy episode of drinking, but not consider it due to alcohol consumption.

Considerably higher levels of hazardous drinking (28.3\% scoring eight or more on the AUDIT or $34.2 \%$ with the lower AUDIT score cut off for women) were found in our self-selecting sample compared to $14 \%$ of the overall Canadian population scoring eight or more on the AUDIT or $18 \%$ excluding those who had not drank alcohol at least once in the past year (lalomiteanu et al., 2014). This discrepancy might indicate that those who take part in studies advertised as being about alcohol may well have higher consumption than a general population survey; this appears true in 
RUNNING HEAD: Alcohol hangover patterns and correlates in Canadian Adults evaluation studies of brief interventions who advertise for current drinkers (Cunningham, 2012). It may also relate to the anonymity of web surveys compared to face-to-face or telephone interviews.

Around $8 \%$ of the sample sought help for alcohol related issues in the past. Latent class two, had a particularly high percentage of previous treatment seeking at around 24\%, and the highest level of alcohol consumption. However, there were no significant associations with the AUDIT problem factor for any of the classes compared to the baseline class. By contrast, the strongest predictor of the number of symptoms experienced was the score on the AUDIT problem factor. Perhaps a global point estimate of hangover symptoms may be useful in highlighting alcohol problems, and future research may wish to explore its potential utility in this regard. It is thought there is a link between alcohol hangover and alcohol problems or dependence, but again, the conclusions are limited by the lack of research in this area (Piasecki et al., 2010; Piasecki et al., 2005). It is likely that the occurrence of drinking in the morning to get started (AUDIT question 4, may be partly due to the withdrawal or hangover effect). Some researchers suggest there is little evidence that hangovers deter alcohol consumption (Mallett et al., 2011). Earleywine (1993) has suggested heavy drinking and hangovers are cyclical, as alcohol is occasionally used to relieve the symptoms of a hangover. Taking an ecological momentary assessment approach, Epler et al. (2014) found limited evidence of a link between the experience of a hangover and the time to next drink except in the presence of interactions with craving and financial stress.

There is limited evidence that any of the classes perceived their alcohol use to be harmful; only class one compared to class four had a significantly higher rating of the harm they considered their alcohol use to cause. The mean rating however, suggests that even though the difference was significant, the risk was deemed to be between no risk and very mild risk for serious future health 
RUNNING HEAD: Alcohol hangover patterns and correlates in Canadian Adults problems. This is particularly concerning for class two who had an AUDIT total score mean of over three points above the hazardous drinking threshold.

Alcohol related flushing is considered a protective factor for alcoholism in Asian communities, but there was little evidence that this protected an individual from drinking to a level that resulted in hangover experience. This sample was predominantly White, with around $5 \%$ of Asian or mixed Asian ethnic origin. As such, this may support the conclusion of Slutske et al. (1995) who suggested that flushing might only limit the alcohol consumption, hangover experience, and potential for alcoholism in Asian communities only, however, the low proportion makes this difficult to analyse in this data.

Few sex differences were found in hangover experience. Unsurprisingly females drank less than males, but sex was neither a significant predictor of total symptoms, nor patterns of symptoms. Perhaps the present or absent nature of the current inquiry may mask some differences in the extent of symptoms. Slutske et al. $(2003 ; 1995)$ have suggested the symptoms may be more severe for females than males; it is not possible to determine this from the current inquiry and future research may wish to explore this further. An alternate explanation may be that because females typically drink less than males, the absence of sex differences in hangover symptoms suggests that there may be an increased sensitivity to hangover effects in women relative to men (assuming consumption levels are controlled for).

This study revealed younger individuals consistently had worse hangovers. Indeed, the youngest individuals were found in the two classes with the most symptoms experienced in the last year (classes one and two). By contrast the symptom free class four had a mean age of 52.4 years (SD=15.5). This finding is supported by Tolstrup et al. (2014) who noted an absence of hangovers as associated with older participants and most severe hangovers amongst the young whilst 
RUNNING HEAD: Alcohol hangover patterns and correlates in Canadian Adults

controlling for a range of demographic and alcohol variables. A number of explanations have been proposed, perhaps older individuals drink less, or with advanced age comes advanced experience leading to higher alcohol tolerance (Hiltunen, 1997), or a knowledge of 'how to drink' (such as choosing beverages without congeners or not mixing drinks (Rohsenow \& Howland, 2010)). There may also be a role for hangover cure or prevention strategies; again an under-researched area.

Hangovers are complex; the unitary explanation of the number of symptoms experienced appears less informative than an exploration of patterns of symptoms experienced. The understanding of the hangover condition is still underdeveloped compared with other areas of alcohol research. A better understanding of the hangover condition will help us better understand the physiological effects of alcohol and the response of the drinker to such experiences, whether these are protective, neutral, or harmful (Swift \& Davidson, 1998). 
RUNNING HEAD: Alcohol hangover patterns and correlates in Canadian Adults

References

Babor, T.F., Higgins-Biddle, J.C., Saunders, J.B., \& Monteiro, M.G. (2001). AUDIT - The alcohol use disorders identification test: Guidelines for use in primary care $2^{\text {nd }}$ Ed. Geneva, World Health Organisation.

Bucholz, K.K., Cadoret, R., Cloninger, C.R., Dinwiddie, S.H., Hesselbrock, V.M., Nurnberger, J.I., Reich, T., Schmidt, I., \& Schuckit, M.A. (1994). A new semi-structured psychiatric interview for use in genetic linkage studies: a report on the reliability of the SSAGA. Journal of studies on alcohol, 55(2), 149-158.

Cunningham, J. A. (2012). Comparison of two internet-based interventions for problem drinkers: randomized controlled trial. Journal of medical Internet research, 14(4), e107.

Earleywine, M. (1993). Hangover moderates the association between personality and drinking problems. Addictive Behaviors, 18, 291-297.

Epler, A. J., Tomko, R. L., Piasecki, T. M., Wood, P. K., Sher, K. J., Shiffman, S., \& Heath, A. C. (2014). Does hangover influence the time to next drink? An investigation using ecological momentary assessment. Alcoholism: Clinical and Experimental Research, 38(5), 1461-1469.

Gjerde, H., Christophersen, A. S., Moan, I. S., Yttredal, B., Walsh, J. M., Normann, P. T., \& Mørland, J. (2010). Research Use of alcohol and drugs by Norwegian employees: a pilot study using questionnaires and analysis of oral fluid. Journal of Occupational Medicine and Toxicology, 5, 13.

Hesse, M., \& Tutenges, S. (2010). Predictors of hangover during a week of heavy drinking on holiday. Addiction, 105(3), 476-483. 
RUNNING HEAD: Alcohol hangover patterns and correlates in Canadian Adults

Hiltunen, A. J. (1997). Acute alcohol tolerance in social drinkers: Changes in subjective effects dependent on the alcohol dose and prior alcohol experience. Alcohol, 14(4), 373-378.

Howland, J., Rohsenow, D. J., Bliss, C. A., Almeida, A. B., Calise, T. V., Heeren, T., \& Winter, M. (2010). Hangover Predicts Residual Alcohol Effects on Psychomotor Vigilance the Morning After Intoxication. Journal of addiction research and therapy, 1, 101.

Howland, J., Rohsenow, D. J., \& Edwards, E. M. (2008). Are some drinkers resistant to hangover? A literature review. Current drug abuse reviews, 1(1), 42-46.

Ialomiteanu, A.R., Hamilton, H.A., Adlaf, E.M., \& Mann, R.E. (2014). CAMH Monitor Report Substance Use Mental Health and Well-Being Among Ontario Adults 1977-2013 (CAMH Research Document Series No 40). Centre for Addiction and Mental Health, Toronto.

Kauhanen, J., Kaplan, G. A., Goldberg, D. D., Cohen, R. D., Lakka, T. A., \& Salonen, J. T. (1997). Frequent hangovers and cardiovascular mortality in middle-aged men. Epidemiology, 310-314.

Mallett, K. A., Varvil-Weld, L., Turrisi, R., \& Read, A. (2011). An examination of college students' willingness to experience consequences as a unique predictor of alcohol problems. Psychology of addictive behaviors, 25(1), 41-47.

McKinney, A., \& Coyle, K. (2007). Next-day effects of alcohol and an additional stressor on memory and psychomotor performance. Journal of studies on Alcohol and Drugs, 68(3), 446-454. 
RUNNING HEAD: Alcohol hangover patterns and correlates in Canadian Adults

Oei, T. P., Hasking, P. A., \& Young, R. M. (2005). Drinking refusal self-efficacy questionnaire-revised (DRSEQ-R): a new factor structure with confirmatory factor analysis. Drug and alcohol dependence, 78(3), 297-307.

Piasecki, T. M., Robertson, B. M., \& Epler, A. J. (2010). Hangover and risk for alcohol use disorders: existing evidence and potential mechanisms. Current drug abuse reviews, 3(2), 92.

Piasecki, T. M., Sher, K. J., Slutske, W. S., \& Jackson, K. M. (2005). Hangover frequency and risk for alcohol use disorders: evidence from a longitudinal high-risk study. Journal of abnormal psychology, 114(2), 223-234.

Robertson, B. M., Piasecki, T. M., Slutske, W. S., Wood, P. K., Sher, K. J., Shiffman, S., \& Heath, A. C. (2012). Validity of the hangover symptoms scale: evidence from an electronic diary study. Alcoholism: Clinical and Experimental Research, 36(1), 171-177.

Rohsenow, D.J., \& Howland, J. (2010). The role of beverage congeners in hangover and other residual effects of alcohol intoxication: a review. Current drug abuse reviews, 3(2), 76-79.

Rohsenow, D. J., Howland, J., Winter, M., Bliss, C. A., Littlefield, C. A., Heeren, T. C., \& Calise, T. V. (2012). Hangover sensitivity after controlled alcohol administration as predictor of post-college drinking. Journal of abnormal psychology, 121(1), 270-275.

Saunders, J. B., Aasland, O. G., Babor, T. F., De la Fuente, J. R., \& Grant, M. (1993). Development of the alcohol use disorders identification test (AUDIT): WHO collaborative project on early detection of persons with harmful alcohol consumption-II. Addiction, 88(6), 791-804. 
RUNNING HEAD: Alcohol hangover patterns and correlates in Canadian Adults

Slutske, W. S., Heath, A. C., Madden, P. A., Bucholz, K. K., Dinwiddie, S. H., Dunne, M. P., ... \& Martin, N. G. (1995). Is Alcohol-Related Flushing a Protective Factor for Alcoholism in Caucasians? Alcoholism: Clinical and Experimental Research, 19(3), 582-592.

Slutske, W. S., Piasecki, T. M., \& Hunt-Carter, E. E. (2003). Development and initial validation of the Hangover Symptoms Scale: Prevalence and correlates of hangover symptoms in college students. Alcoholism: Clinical and Experimental Research, 27(9), 1442-1450.

Smith, G. W., Farrell, M., Bunting, B. P., Houston, J. E., \& Shevlin, M. (2011). Patterns of polydrug use in Great Britain: Findings from a national household population survey. Drug and Alcohol Dependence, 113(2), 222-228.

Smith, G. W., \& Shevlin, M. (2008). Patterns of alcohol consumption and related behaviour in Great Britain: a latent class analysis of the alcohol use disorder identification test (AUDIT). Alcohol and Alcoholism, 43(5), 590-594.

Swift, R., \& Davidson, D. (1998). Alcohol hangover. Alcohol Health Res World, 22, 54-60.

Tolstrup, J. S., Stephens, R., \& Grønbaek, M. (2014). Does the severity of hangovers decline with age? Survey of the incidence of hangover in different age groups. Alcoholism: Clinical and Experimental Research, 38(2), 466-470.

Wiese, J. G., Shlipak, M. G., \& Browner, W. S. (2000). The alcohol hangover. Annals of internal medicine, 132(11), 897-902. 
RUNNING HEAD: Alcohol hangover patterns and correlates in Canadian Adults

Table 1: Demographic, alcohol and hangover characteristics of the sample of 565 Canadian adults.

\begin{tabular}{|c|c|c|c|c|c|}
\hline & \multirow{2}{*}{$\begin{array}{l}\text { Valid } \\
\mathrm{n}\end{array}$} & \multicolumn{3}{|c|}{ Mean (SD) or $\mathrm{n}(\%)$} & \multirow{2}{*}{$\begin{array}{l}\mathrm{T} / \mathrm{X}^{2}(\mathrm{df}) \mathrm{p} \text { between } \\
\text { Males and Females }\end{array}$} \\
\hline & & Total & Males & Females & \\
\hline Female & 565 & $307(54.3 \%)$ & & & \\
\hline Age (in years) & 565 & $46.8(15.6)$ & $49.6(14.9)$ & $44.5(15.9)$ & $t(563)=-4.0 ; p<.005$ \\
\hline Highest level of Education completed & 538 & & & & \\
\hline Did not complete High School & & $10(1.8 \%)$ & $5(2.0 \%)$ & $5(1.6 \%)$ & $X^{2}(3)=4.1 ; p=.256$ \\
\hline High School & & $184(32.9 \%)$ & $74(29.1 \%)$ & $10(35.9 \%)$ & \\
\hline Community College/Trade school & & $180(32.1 \%)$ & $85(33.5 \%)$ & $95(31.0 \%)$ & \\
\hline University Degree & & $164(29.3 \%)$ & $83(32.7 \%)$ & $81(26.5 \%)$ & \\
\hline Other (excluded from analyses) & & $22(3.9 \%)$ & $7(2.8 \%)$ & $15(4.9 \%)$ & \\
\hline Race & 560 & & & & \\
\hline White & & $505(90.2 \%)$ & $228(89.4 \%)$ & $277(90.8 \%)$ & $X^{2}(2)=.5 ; p=.789$ \\
\hline Asian or mixed Asian & & $27(4.8 \%)$ & $14(5.5 \%)$ & $13(4.3 \%)$ & \\
\hline Other & & $28(5.0 \%)$ & $13(5.1 \%)$ & $15(5.1 \%)$ & \\
\hline Marital status & 563 & & & & \\
\hline Married/cohabiting & & $343(60.9 \%)$ & $156(60.5 \%)$ & $187(61.3 \%)$ & $X^{2}(1)=.0 ; p=.838$ \\
\hline Other & & $220(39.1 \%)$ & $102(39.5 \%)$ & $118(38.7 \%)$ & \\
\hline Employment & 563 & & & & \\
\hline Part-time & & $66(11.7 \%)$ & $29(11.2 \%)$ & $37(12.1 \%)$ & $X^{2}(3)=11.6 ; p=.009$ \\
\hline Full-time & & $253(44.9 \%)$ & $132(51.2 \%)$ & $121(39.7 \%)$ & \\
\hline Student & & $27(4.8 \%)$ & $6(2.3 \%)$ & $21(6.9 \%)$ & \\
\hline Otherwise economically inactive & & $217(38.5 \%)$ & $91(35.3 \%)$ & $126(41.3 \%)$ & \\
\hline Annual Household Income & 554 & & & & \\
\hline$<30,000 C A D$ & & $115(20.8 \%)$ & $53(20.8 \%)$ & $62(20.7 \%)$ & $X^{2}(3)=1.8 ; p=.625$ \\
\hline $30,000-49,000$ CAD & & $119(21.5 \%)$ & $49(19.2 \%)$ & $70(23.4 \%)$ & \\
\hline $50,000-79,000 C A D$ & & $157(28.3 \%)$ & $73(28.6 \%)$ & $84(28.1 \%)$ & \\
\hline$>80,000$ CAD & & $163(29.4 \%)$ & $80(31.4 \%)$ & $83(27.8 \%)$ & \\
\hline
\end{tabular}


RUNNING HEAD: Alcohol hangover patterns and correlates in Canadian Adults

\begin{tabular}{|c|c|c|c|c|c|}
\hline \multicolumn{6}{|l|}{ Alcohol variables } \\
\hline AUDIT Consumption score & 565 & $4.1(2.3)$ & $4.7(2.4)$ & $3.7(2.2)$ & $t(563)=-4.9 ; p<.005$ \\
\hline AUDIT Problems score & 538 & $2.2(3.8)$ & $2.6(4.6)$ & $1.9(3.5)$ & $t(498.8)=-1.7 ; p=.094$ \\
\hline AUDIT total score & 538 & $6.4(5.7)$ & $7.2(6.2)$ & $5.7(5.1)$ & $t(472.8)=-3.1 ; p=.002$ \\
\hline Social Pressure DRSEQ score & 509 & $14.0(5.3)$ & $13.5(5.2)$ & $14.5(5.4)$ & $t(563)=3.0 ; p=.003$ \\
\hline Alcohol related help-seeking & 563 & $46(8.2 \%)$ & $27(10.5 \%)$ & $19(6.2 \%)$ & $X^{2}(1)=3.3 ; p=.068$ \\
\hline Blush/flush with 1 or 2 drinks & 521 & $180(34.5 \%)$ & $42(18.2 \%)$ & $138(47.6 \%)$ & $X^{2}(1)=49.2 ; p<.005$ \\
\hline \multicolumn{6}{|l|}{ Hangover symptoms } \\
\hline Felt extremely thirsty or dehydrated & 557 & $278(49.9 \%)$ & $124(48.6 \%)$ & $154(51.0 \%)$ & $X^{2}(1)=.3 ; p=.578$ \\
\hline Felt more tired than usual & 557 & $235(42.4 \%)$ & $98(38.4 \%)$ & $137(45.4 \%)$ & $X 2(1)=2.7 ; p=.099$ \\
\hline Experienced a headache & 558 & $268(48.0 \%)$ & $112(43.9 \%)$ & $156(51.5 \%)$ & $X 2(1)=3.2 ; p=.075$ \\
\hline Felt very nauseous & 554 & $158(28.5 \%)$ & $61(24.0 \%)$ & $97(32.3 \%)$ & $X 2(1)=4.7 ; p=.031$ \\
\hline Vomited & 556 & $109(19.6 \%)$ & $45(17.7 \%)$ & $64(21.2 \%)$ & $X 2(1)=1.1 ; p=.304$ \\
\hline Felt very weak & 558 & $112(20.1 \%)$ & $48(18.8 \%)$ & $64(21.1 \%)$ & $X 2(1)=.5 ; p=.499$ \\
\hline Had difficulty concentrating & 554 & $124(22.4 \%)$ & $57(22.5 \%)$ & $67(22.3 \%)$ & $X 2(1)=.0 ; p=.939$ \\
\hline More sensitive to light and sound than & 553 & $106(19.2 \%)$ & $37(14.6 \%)$ & $69(23.1 \%)$ & $X 2(1)=6.4 ; p=.011$ \\
\hline \multicolumn{6}{|l|}{ usual } \\
\hline Sweated more than usual & 553 & $101(18.3 \%)$ & $48(18.8 \%)$ & $53(17.8 \%)$ & $X 2(1)=.1 ; p=.753$ \\
\hline Had a lot of trouble sleeping & 551 & $104(18.9 \%)$ & $44(17.5 \%)$ & $60(20.0 \%)$ & $X 2(1)=.6 ; p=.461$ \\
\hline Was anxious & 553 & $81(14.6 \%)$ & $40(15.7 \%)$ & $41(13.7 \%)$ & $X 2(1)=.5 ; p=.500$ \\
\hline Felt depressed & 556 & $107(19.2 \%)$ & $47(18.4 \%)$ & $60(19.9 \%)$ & $X 2(1)=.2 ; p=.654$ \\
\hline Experienced trembling or shaking & 548 & $51(9.3 \%)$ & $25(9.9 \%)$ & $26(8.8 \%)$ & $X 2(1)=.2 ; p=.648$ \\
\hline Any of the above in the past year & 528 & $343(65.0 \%)$ & $152(62.8 \%)$ & $191(66.8 \%)$ & $X 2(1)=.9 ; p=.340$ \\
\hline Mean \# symptoms & 528 & $3.3(3.6)$ & $3.0(3.5)$ & $3.5(3.6)$ & $t(526)=1.4 ; p=.176$ \\
\hline
\end{tabular}


RUNNING HEAD: Alcohol hangover patterns and correlates in Canadian Adults

Table 2: Results of the multivariate regression analysis predicting total number of hangover symptoms

experienced in the past year $(n=478)$.

Unstandardized Standardized $\quad$ SE $\quad$ p value

b Beta

Intercept

Age (in years)

Male sex

Audit consumption

Audit problems

Sought treatment for alcohol problems

Flush/blush when drink

Drinking refusal self-efficacy social

pressure

Perceived harm from alcohol

\subsection{6}

$-0.06$

$-0.27$

0.30

0.33

$-0.06$

1.68

$-0.06$

$-0.15$

0.04

0.58

0.06

0.06

0.045 
RUNNING HEAD: Alcohol hangover patterns and correlates in Canadian Adults

Table 3: Demographic and alcohol use characteristics of each hangover experience class ( $n=559$ )

Mean (SD) unless otherwise stated

\begin{tabular}{|c|c|c|c|}
\hline \multirow[b]{2}{*}{ Class 1- multiple } & \multicolumn{3}{|l|}{ Class 2- thirsty, } \\
\hline & tired, headache, & Class 3- thirsty, & Class 4- symptom \\
\hline symptoms & & tired, headache & free \\
\hline & nausea, vomiting & & \\
\hline 39.68 (14.3) & $38.6(11.2)$ & $47.3(14.9)$ & $52.4(15.5)$ \\
\hline
\end{tabular}

Age (years)

$39.1 \%$

$41.3 \%$

$48.0 \%$

$48.4 \%$

Percentage stating monthly or

$34.8 \%$

$58.7 \%$

$26.8 \%$

$12.6 \%$

more frequent drinking of 5 or

more drinks on occasion

AUDIT total

AUDIT consumption

AUDIT problems

Sought treatment for alcohol

problems

Flush/blush when drink

$43.1 \%$

Drinking refusal self-efficacy social 13.1 (4.6)

$4.7(1.9)$

$2.5(3.4)$

$5.8 \%$

$24.2 \%$

$49.5 \%$

$39.5 \%$

$22.6 \%$

pressure

Perceived harm from alcohol

$1.6(0.9)$

$2.6(1.3)$

$1.8(1.0)$

$1.3(0.6)$ 
RUNNING HEAD: Alcohol hangover patterns and correlates in Canadian Adults

Table 4: Results of the multinomial logistic regression analysis of demographic, alcohol, and other correlates with hangover class membership (n=481) * denotes significant at 0.05 level

OR (95\% Cl) compared to Class 4- no hangover $(\mathrm{n}=203)$

\begin{tabular}{|c|c|c|}
\hline $\begin{array}{l}\text { Class } 1 \text { - multiple } \\
\text { symptoms }\end{array}$ & $\begin{array}{l}\text { Class 2- thirsty, tired, } \\
\text { headache, nausea, vomiting }\end{array}$ & $\begin{array}{l}\text { Class 3- thirsty, tired, } \\
\text { headache }(n=115)\end{array}$ \\
\hline & & \\
\hline $0.9(0.9-0.95)^{\star}$ & $0.9(0.9-0.97)^{\star}$ & $0.98(0.97-0.99)^{\star}$ \\
\hline $0.7(0.3-1.3)$ & $0.6(0.3-1.2)$ & $0.9(0.6-1.5)$ \\
\hline $1.5(1.2-1.8)^{\star}$ & $1.4(1.2-1.7)^{\star}$ & $1.2(1.1-1.5)^{\star}$ \\
\hline $1.3(0.98-1.6)$ & $1.2(0.9-1.5)$ & $1.0(0.8-1.2)$ \\
\hline $2.7(0.6-12.3)$ & $1.1(0.2-7.1)$ & $2.2(0.6-8.5)$ \\
\hline $3.2(1.6-6.3)^{\star}$ & $1.8(0.99-3.5)$ & $2.1(1.3-3.6)^{\star}$ \\
\hline $0.9(0.9-1.01)$ & $1.0(0.9-1.01)$ & $0.9(0.9-0.99)^{\star}$ \\
\hline $1.8(1.2-2.6)^{\star}$ & $1.0(0.6-1.6)$ & $1.4(0.9-2.0)$ \\
\hline
\end{tabular}


RUNNING HEAD: Alcohol hangover patterns and correlates in Canadian Adults

Figure 1: Patterns of hangover symptoms experienced in the last year in the sample of 559 Canadian adults.

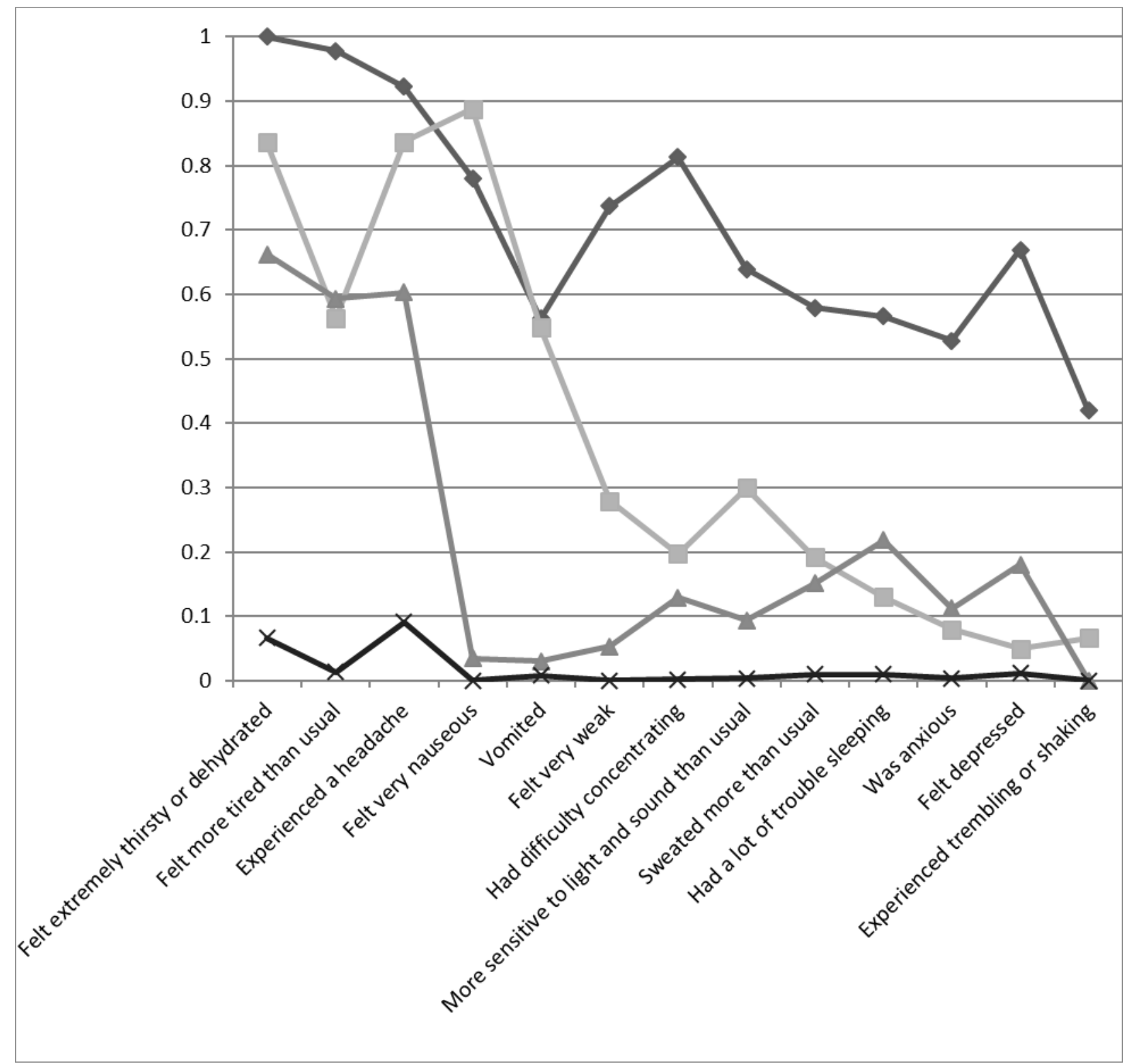

—Class 1: Multiple symptoms n=116 (20.8\%)

- Class 2: Thirsty, tired, headache, nausea, vomiting n=71 (12.7\%)

-Class 3: Thirsty, tired, headache $n=134$ (23.9\%)

$\leftarrow$ Class 4: Symptom free $n=238(42.5 \%)$ 
RUNNING HEAD: Alcohol hangover patterns and correlates in Canadian Adults 